\title{
Caracteres anatômicos de folha e caule de Calea uniflora Less., Asteraceae
}

\author{
Jane M. Budel ${ }^{1 *}$, Márcia R. Duarte ${ }^{1}$, Paulo V. Farago ${ }^{2}$, Inês J.M. Takeda \\ ${ }^{1}$ Laboratório de Farmacognosia, Universidade Federal do Paraná, Rua Lothário Meissner, 632, Jardim Botânico, \\ 80210-170, Curitiba, PR, Brasil, \\ ${ }^{2}$ Departamento de Ciências Farmacêuticas, Universidade Estadual de Ponta Grossa, Av. Carlos Cavalcanti 4748, \\ 84030-900, Ponta Grossa, PR, Brasil, \\ ${ }^{3}$ Departamento de Tecnologia de Alimentos e Medicamentos, Universidade Estadual de Londrina, Caixa Postal \\ 6001, 86051-970, Londrina, PR, Brasil
}

\begin{abstract}
RESUMO: Diversas espécies de Calea são utilizadas como medicinais e vários estudos químicos têm sido conduzidos para identificar compostos relevantes no gênero, no entanto, poucos enfocam aspectos morfoanatômicos. Este trabalho tem por objetivo caracterizar morfologicamente a folha e o caule de Calea uniflora Less., a fim de fornecer subsídios para a identificação da espécie. $\mathrm{O}$ material foi submetido às microtécnicas fotônica e eletrônica de varredura usuais. A lâmina foliar possui epiderme uniestratificada revestida por cutícula delgada e estriada. Em ambas as faces, ocorrem estômatos anomocíticos e anisocíticos, além de tricomas glandulares e tectores. Estes são pluricelulares e unisseriados, com ápice agudo. Os glandulares podem ser pluricelulares e plurisseriados ou capitados e inseridos em depressão na epiderme. O mesofilo é isobilateral e a nervura central é biconvexa, sendo percorrida por um feixe vascular colateral. O caule mostra secção circular e epiderme unisseriada, com tricomas similares aos da folha. Colênquima angular e clorênquima alternam-se no córtex, fibras perivasculares apõem-se ao floema, o arranjo vascular é colateral e a medula compõe-se de células parenquimáticas. Dutos secretores acompanham o sistema vascular na folha e no caule.
\end{abstract}

Unitermos: Asteraceae, Calea uniflora, morfoanatomia.

\begin{abstract}
Anatomical characters of the leaf and stem of Calea uniflora Less., Asteraceae". Various species of Calea are considered medicinal and several investigations have been carried out to identify relevant chemical substances in the genus, however, few studies have dealt with morphoanatomical aspects. This work aimed to analyse the morphological characters of the leaf and stem of Calea uniflora Less., in order to contribute for the species identification. The plant material was prepared according to usual light and scanning microtechniques. The blade has uniseriate epidermis coated with thin and striate cuticle. Anomocytic and anisocytic stomata are seen on both surfaces, as well as glandular and non-glandular trichomes. The latter is pluricellular and uniseriate, with acute apex. The glandular trichomes are pluricellular and multiseriate or capitate and located in epidermal depression. The mesophyll is isobilateral, and the midrib is biconvex and traversed by a collateral vascular bundle. The stem shows circular transection and uniseriate epidermis, with trichomes similar to the leaf. Angular collenchyma and chlorenchyma alternate in the cortex, perivascular fibres adjoin the phloem, the vascular arrangement is collateral and the pith consists of parenchymatic cells. Secretory ducts are associated with the vascular system of the leaf and stem.
\end{abstract}

Keywords: Asteraceae, Calea uniflora, morpho-anatomy.

\section{INTRODUÇÃO}

O gênero Calea pertence à família Asteraceae e ocorre nas Américas do Sul e Central e contém 110 espécies aproximadamente (Karis; Ryding, 1994). Diversas espécies de Calea têm sido estudadas sob o aspecto fitoquímico: Calea berteriana DC. (Ober et al., 1985a,b), C. crocinervosa Wussow, Urbatsch \& G.A. Sullivan (Ortega, 1989), C. leptocephala S.F. Blake (Ober et al., 1986), C. megacephala B.L. Rob. \& Greenm. (Ober et al., 1987), C. nelsonii Rob. \& Greenm. (Martinez et al., 1987), C. pinnatifida (R. Br.) Less. (Ferreira et al.,
1978; Ferreira et al., 1980), C. prunifolia Kunth (Ober et al., 1985a) e C. uniflora Less. (Nascimento et al., 2002; Nascimento; Oliveira, 2004).

Várias espécies do táxon são empregadas popularmente como medicinais para o tratamento de problemas digestivos e alguns estudos demonstraram atividades farmacológicas, a exemplo das atividades hipoglicêmica (Ramos et al., 1992) e antiplasmódica (Kohler et al., 2002) de C. zacatechichi Schltdl., antifúngica de C. clematidea Baker (Flach et al., 2002) e $C$. uniflora (Nascimento et al., 2004), anti-hipertensiva de $C$. glomerata Klatt (Guerrero et al., 2002), tripanosomicida 
de C. uniflora (Nascimento et al., 2002; Nascimento et al., 2004) e amebicida de C. pinnatifida (Machado Filho, 1930; Vaz, 1949).

O presente trabalho tem por objetivo analisar a anatomia foliar e caulinar de Calea uniflora Less., Asteraceae, a fim de fornecer subsídios para a identificação da espécie.

\section{MATERIAL E MÉTODOS}

A coleta do material botânico foi realizada na Fazenda São Maximiano, situada na região da Serra do Sudoeste, em Guaíba, Rio Grande do Sul $\left(30^{\circ} 10^{\prime} \mathrm{S}\right.$ e $51^{\circ}$ $20^{\prime} \mathrm{W}$ ), em dezembro de 2003 . A exsicata foi identificada por taxonomista e encontra-se depositada no Instituto de Ciências Naturais (ICN) da Universidade Federal do Rio Grande do Sul sob o número ICN 49024.

Foram utilizadas folhas adultas e fragmentos de caules a partir de $5 \mathrm{~cm}$ do ápice da planta. A fixação do material foi realizada no próprio local da coleta, utilizandose FAA 70 (Johansen, 1940), sendo posteriormente armazenado em álcool etílico a 70\% (Berlyn; Miksche, 1976).

Foram preparadas lâminas semipermanentes à mão livre, a partir de secções transversais e longitudinais. Lâminas permanentes foram obtidas de material fixado, desidratado em série etanólica, infiltrado e incluído em glicol metacrilato (Kraus; Arduin, 1997). O material incluído foi então seccionado no micrótomo Spencer 820. Os cortes foram submetidos à coloração com azul de astra e fucsina básica (Roeser, 1962) ou azul de toluidina (O’Brien et al., 1965).

Para a realização dos testes microquímicos foram feitas secções transversais à mão livre do material e os reativos empregados foram: solução de floroglucina clorídrica para verificação de lignina (Foster, 1949), Sudam III para substâncias lipofílicas (Sass, 1951), cloreto férrico para compostos fenólicos (Johansen, 1940) e lugol para amido (Berlyn; Miksche, 1976).

A análise ultra-estrutural de superfície (microscopia eletrônica de varredura - MEV) foi realizada em lâmina foliar e caule e, para tal procedimento, as amostras foram fixadas em FAA 70, desidratadas em série etanólica crescente e pelo ponto crítico no equipamento Balzers CPD-010 e, após montagem em suporte, submetidas à metalização com ouro no aparelho Balzers Sputtering SCD-030. As eletromicrografias foram realizadas no microscópio eletrônico de varredura Jeol JSM 6360 LV (Souza, 1998).

\section{RESULTADOS}

Calea uniflora Less., Asteraceae (Figura 1), apresenta lâmina foliar com epiderme uniestratificada (Figura 4), cujas células possuem paredes anticlinais ligeiramente onduladas em vista frontal (Figuras 2, 3). Uma cutícula delgada e estriada recobre o sistema de revestimento (Figura 9). A folha é anfiestomática e apresenta estômatos anisocítico e anomocítico, predominando estes últimos (Figuras 2, 3), que se localizam no mesmo nível das demais células epidérmicas (Figura 4). Os tricomas glandulares estão inseridos em pequena depressão na epiderme e podem ser pluricelulares e bisseriados (Figuras 5, 7) ou capitados com pedicelo unicelular e cabeça globóide (Figuras 6, 7). Tricomas tectores pluricelulares (aproximadamente 5-8 células), unisseriados, de base alargada e célula terminal afilada são circundados por células epidérmicas dispostas em roseta (Figuras 8, 9).

O mesofilo é do tipo isobilateral, sendo constituído por parênquima paliçádico, com células dispostas em aproximadamente 2-3 camadas junto à face adaxial e 1-2 estratos adjacentes à abaxial; o parênquima esponjoso é formado por cerca de 4-6 camadas (Figura 4). Feixes vasculares colaterais de pequeno porte, distribuídos na região mediana do mesofilo, são envoltos por bainha parenquimática e podem estar associados a dutos secretores (Figura 4).

A nervura central, em secção transversal, possui formato biconvexo. A epiderme é uniestratificada e, subjacentemente, o clorênquima se interrompe e são encontradas aproximadamente 6 camadas de colêquima do tipo angular junto à face adaxial e 3-4 camadas na face abaxial. Um feixe vascular de grande porte, que pode ser ladeado por dois feixes menores, do tipo colateral, encontra-se mergulhado no parênquima fundamental. Dutos secretores são observados nas proximidades do sistema vascular e apresentam epitélio uniestratificado composto por cerca de 5 células, de citoplasma denso e núcleo conspícuo. O xilema é constituído de elementos traqueais dispostos em fileiras e separados por células parenquimáticas, e a zona cambial é evidente (Figura $10)$.

O caule, em estrutura secundária incipiente, apresenta contorno circular em secção transversal e epiderme e tricomas com as mesmas características citadas para a folha. Em posição adjacente à epiderme, encontramse faixas de colênquima do tipo angular em alternância ao parênquima cortical com muitos cloroplastos. Limitando internamente o córtex, observa-se um estrato de células parenquimáticas contendo amiloplastos, constituindo a bainha amilífera. Nas proximidades desta, em direção aos feixes vasculares, dutos secretores de epitélio unisseriado, formados por 4-7 células são observados (Figura 12). $\mathrm{O}$ cilindro vascular possui feixes do tipo colateral (Figura 11) e em aposição ao sistema floemático notam-se calotas de fibras perivasculares (Figuras 11, 12). No xilema, os elementos traqueais distribuem-se em fileiras separadas por células parenquimáticas em processo de lignificação. A região medular possui parênquima com células relativamente grandes, com paredes delgadas e campos primários de pontoação. 


\section{DISCUSSÃO}

Para Metcalfe e Chalk (1950), os estômatos podem ser anomocíticos e anisocíticos na família Asteraceae, com predominância do primeiro tipo, e podem ocorrer em ambas as faces, como observado em C. uniflora. No entanto, em C. pinnatifida (R. Br.) Less., Oliveira et al. (1991) descrevem apenas o tipo anomocítico e exclusivamente na face abaxial.

Metcalfe (1979) relata que a presença de tricomas pode ter valor taxonômico, sendo a descrição destes relevante. Nesse sentido, Oliveira et al. (1993) afirmam que essas estruturas epidérmicas constituem características de grande valia na diagnose da droga vegetal, principalmente quando este se apresenta fragmentado ou mesmo pulverizado. Tricomas tectores pluricelulares unisseriados foram encontrados em $C$. uniflora e tricomas similares também foram descritos para outras espécies de Asteraceae (Rodrigues et al., 1996; Oliveira et al., 2000; Tavares et al., 2000). Tricomas glandulares pluricelulares, capitados foram encontrados em C. uniflora. Essas mesmas categorias foram observadas para outras espécies de Asteraceae do gênero Ageratum (Oliveira et al., 1993) e Mikania (Neves; Sá, 1991; Oliveira et al., 1999; Oliveira et al., 2000). Entretanto, Oliveira et al. (1991) descrevem os tricomas glandulares encontrados em C. pinnatifida mostrando pedicelo pluricelular unisseriado e glândula unicelular, os quais, caracteristicamente, apresentam forma encurvada.

Em Magnoliopsida, o mesofilo é diferenciado comumente em parênquima paliçádico e esponjoso (Cutter, 1986). Para Metcalfe e Chalk (1950), o mesofilo da família Asteraceae é variável. A organização dos parênquimas fotossintetizantes na espécie estudada tem correspondência ao tipo isobilateral. Todavia, foi observado mesofilo dorsiventral em C. pinnatifida (Myiake et al., 1986).

$\mathrm{Na}$ maioria das Asteraceae o aparelho excretor, assim denominado por Barroso (1991), está representado por dois tipos de estruturas: os canais esquizógenos e as células laticíferas. C. uniflora apresenta dutos secretores asssociados ao sistema vascular, bem como os observados por Neves e Sá (1991) para Mikania glomerata Sprengel, por Rodrigues et al. (1996) para Mikania malacolepsis Robinson e por Jorge et al. (1999) para Achillea millefolium L. Esses últimos autores descrevem os dutos secretores como tubos oleíferos retos e calibrosos percorrendo o mesofilo paralelamente aos feixes vasculares.

Em muitas Magnoliophyta, os feixes vasculares são total ou parcialmente circundados por uma bainha morfologicamente distinta formada por uma ou mais camadas de células. Nas Magnoliopsida, os feixes de maior porte localizam-se na nervura central e os de pequeno porte estão imersos no mesofilo (Esau, 1974; Cutter, 1986). Com referência a esse aspecto, em C. uniflora o feixe vascular de pequeno porte está localizado no parênquima esponjoso e envolto por bainha parenquimática. Oliveira et al. (1991) relatam que os feixes vasculares de pequeno porte de $C$. pinnatifida podem ser observados na região do mesofilo e sempre estão associados aos dutos secretores.

C. uniflora evidencia colênquima do tipo angular com 6 camadas na face adaxial e 3-4 camadas na face abaxial. Esses dados vão ao encontro dos relatos de Oliveira et al. (1991) para C. pinnatifida, onde os autores descrevem o colênquima como mais desenvolvido na face epidérmica superior. A inobservância de cristais em C. uniflora coincide com o descrito para C. pinnatifida (Myiake et al., 1986).

O caule de C. uniflora, em estrutura secundária incipiente, apresenta formato praticamente circular. Adjacentemente à epiderme, ocorre a presença de colênquima do tipo angular em faixa contínua. Essa disposição está de acordo com o observado em $C$. pinnatifida, onde os autores descrevem que esse tipo de colênquima é relativamente mais desenvolvido nas regiões mais salientes do caule (Oliveira et al., 1991).

Entre as Magnoliophyta, a endoderme com estrias de Caspary não é comum em caule e pecíolo, e na folha ocorre raramente, podendo ser tratada como bainha do feixe (Lersten, 1997). Na família Asteraceae, a endoderme é bem definida e vários tipos podem ocorrer em diferentes gêneros e espécies, mostrando-se suberizadas ou como bainha amilífera (Metcalfe; Chalk, 1950). Essa última corresponde às camadas mais internas do córtex, que contêm amido nos caules jovens (Esau, 1974; Rudall, 1994). De modo similar, limitando internamente o córtex, o caule de C. uniflora mostra uma bainha amilífera. Nas proximidades desta, observam-se dutos secretores, relatados também por Oliveira et al. (1991) para o caule de C. pinnatifida. Esses autores relatam a presença de dutos secretores tanto na região cortical, quanto na região medular.

O sistema vascular é o responsável pela maior parte da variação na estrutura do caule. Em Magnoliopsida, apresenta-se em forma cilíndrica entre o córtex e a medula (Esau, 1974). Para Metcalfe e Chalk (1950), é comum nas Asteraceae a presença de feixes vasculares do tipo colateral no caule. Oliveira et al. (1993) afirmam que uma característica relevante na diagnose da droga vegetal é a calota de fibras localizadas sobre os feixes vasculares. Para C. pinnatifida, Oliveira et al. (1991) relatam a presença de feixes vasculares colaterais protegidos por calota fibrosa do lado do floema, características também encontradas na espécie em questão.

\section{CONCLUSÃO}

Dentre os vários caracteres anatômicos observados em C. uniflora, podem ser destacados: tricomas tectores pluricelulares unisseriados, tricomas glandulares pluricelulares bisseriados ou capitados com pedicelo unicelular e cabeça globóide, estômatos predominantemente anomocíticos, dutos secretores associados a feixes vasculares colaterais, que no seu 
conjunto contribuem fornecendo dados complementares para a caracterização da droga vegetal. ao Centro de Microscopia Eletrônica da Universidade Federal do Paraná pelas eletromicrografias.

\section{AGRADECIMENTOS}

Os autores agradecem ao taxonomista Prof.

Dr. N.I. Matzenbacher pela identificação da espécie e

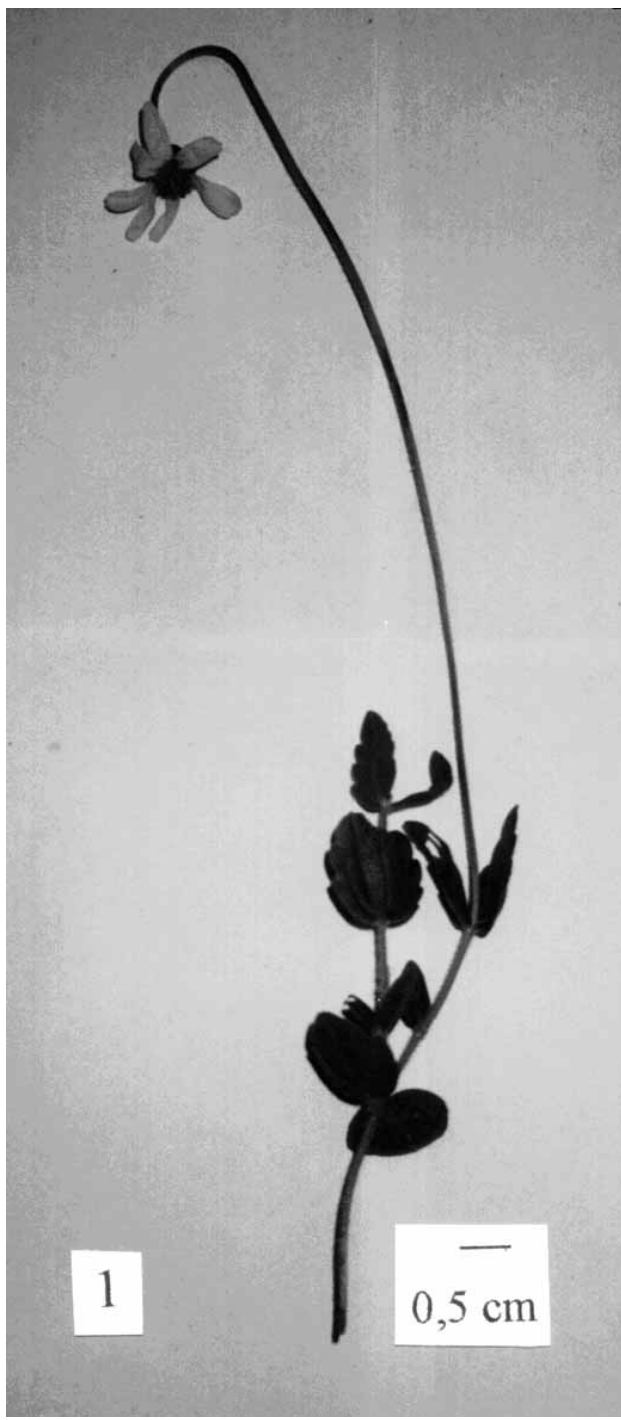

Figura 1. Calea uniflora Less., Asteraceae: Aspecto geral.

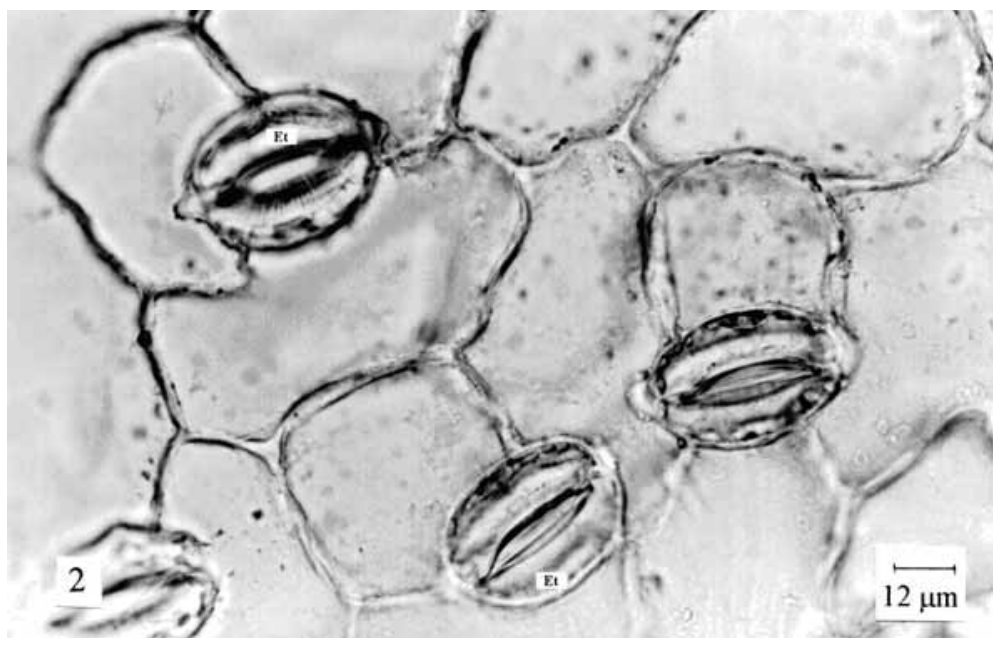

Figura 2. C. uniflora: Vista frontal da epiderme foliar, face adaxial, mostrando estômatos anomocíticos (Et).

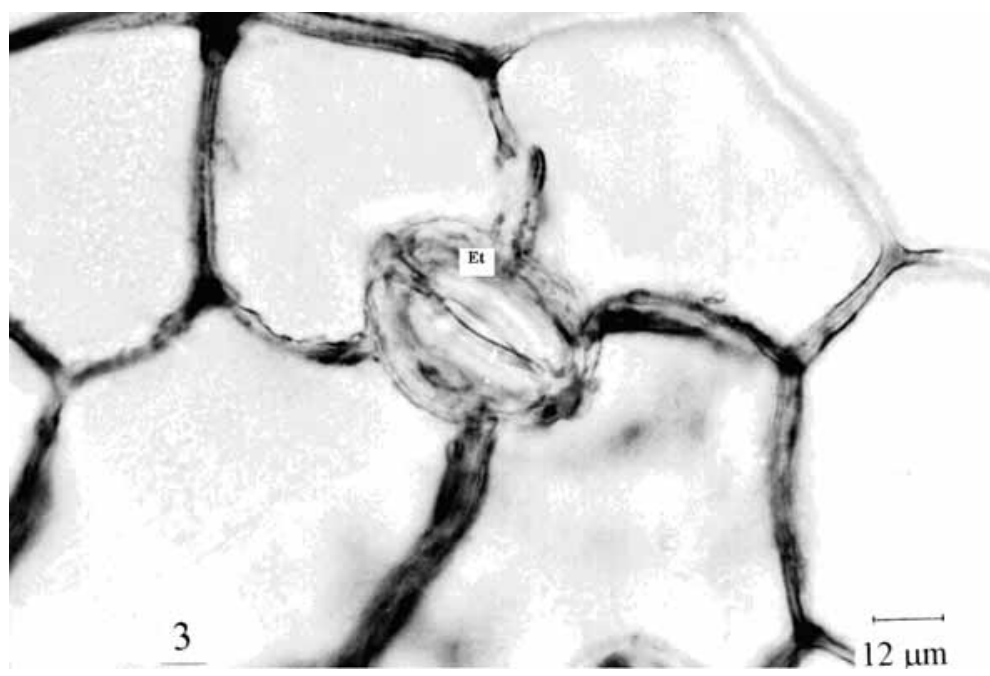

Figura 3. C. uniflora: Vista frontal da epiderme foliar, face abaxial, destacando estômato anomocítico (Et). 


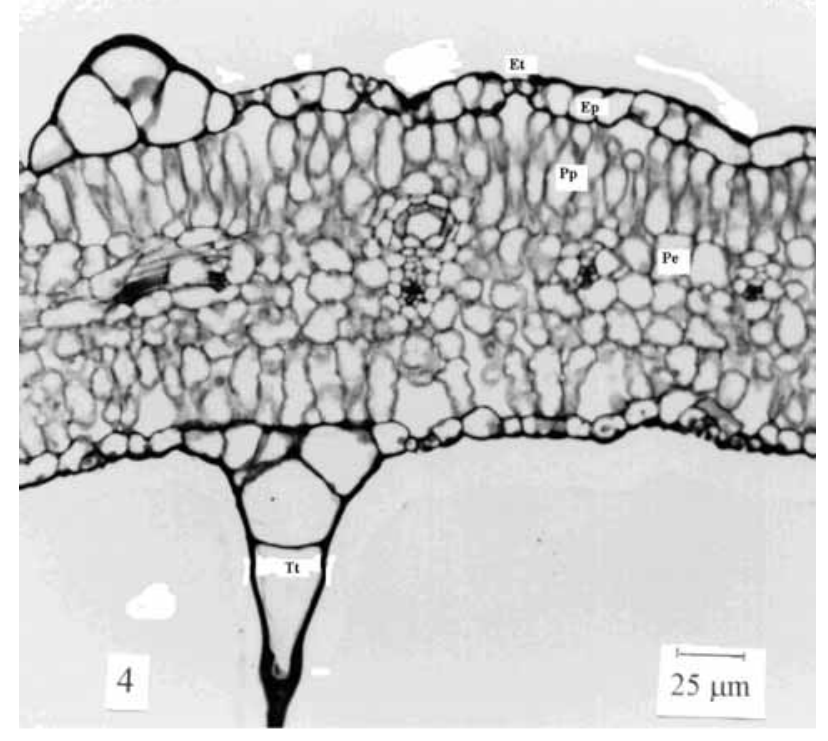

Figura 4. C. uniflora: Lâmina foliar evidenciando mesofilo isobilateral, epiderme uniestratificada (Ep), parênquima paliçádico $(\mathrm{Pp})$, parênquima esponjoso $(\mathrm{Pe})$, estômato no mesmo nível das demais células epidérmicas $(\mathrm{Et})$ e tricoma tector $(\mathrm{Tt})$.
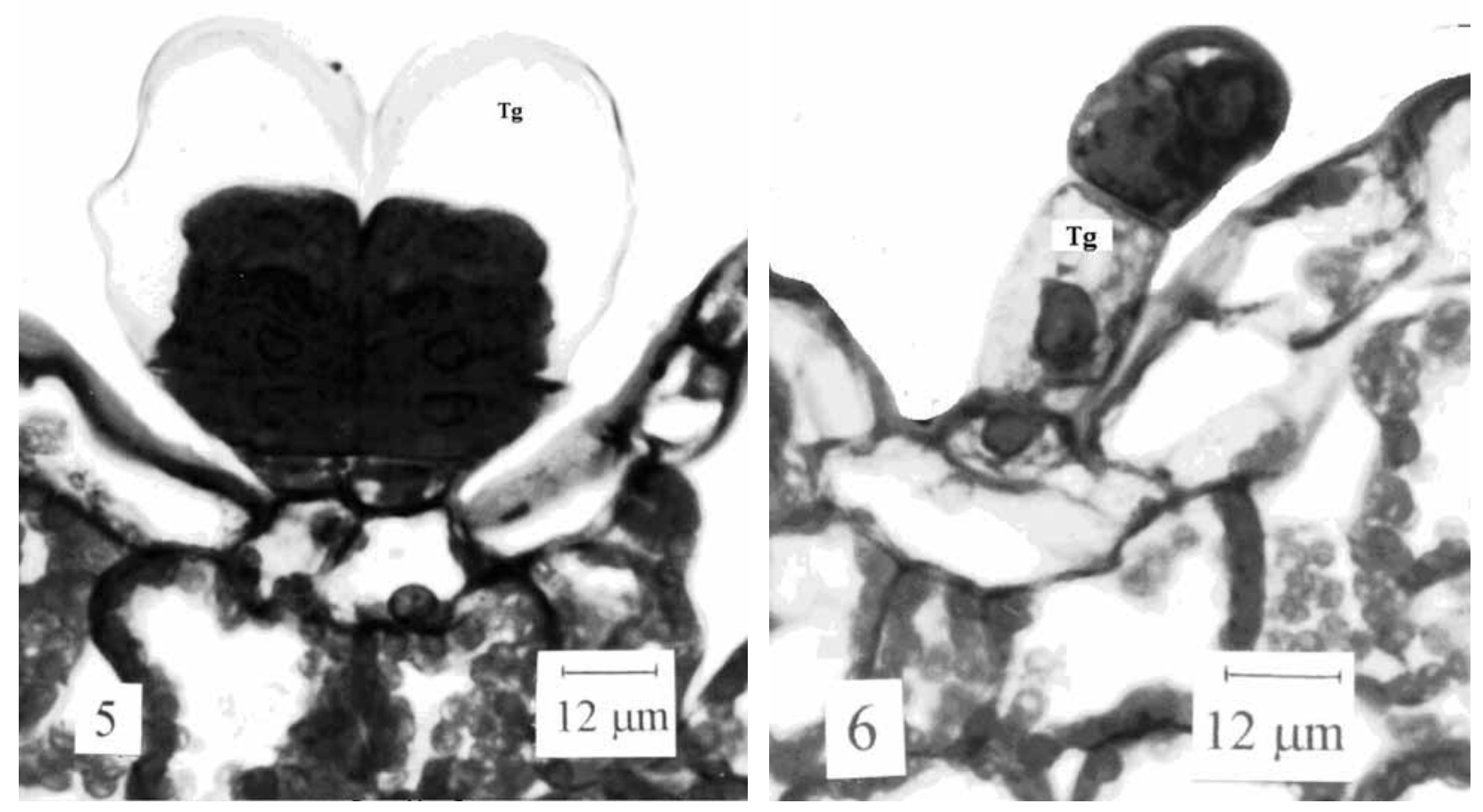

Figura 5. C. uniflora: Tricoma glandular pluricelular plurisseriado

Figura 6. C. uniflora: Tricoma glandular capitado (Tg). (Tg). 


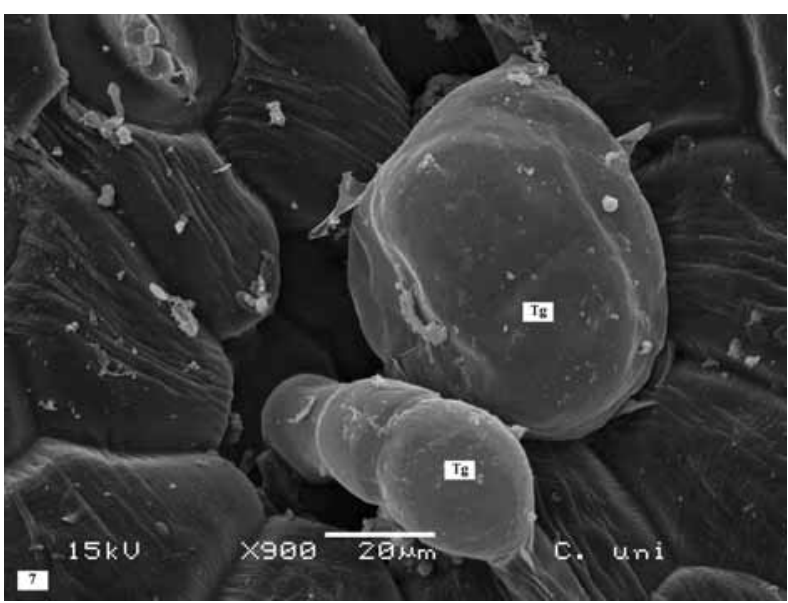

Figura 7. C. uniflora: Vista frontal da epiderme, face abaxial, indicando tricomas glandulares (MEV 900x).

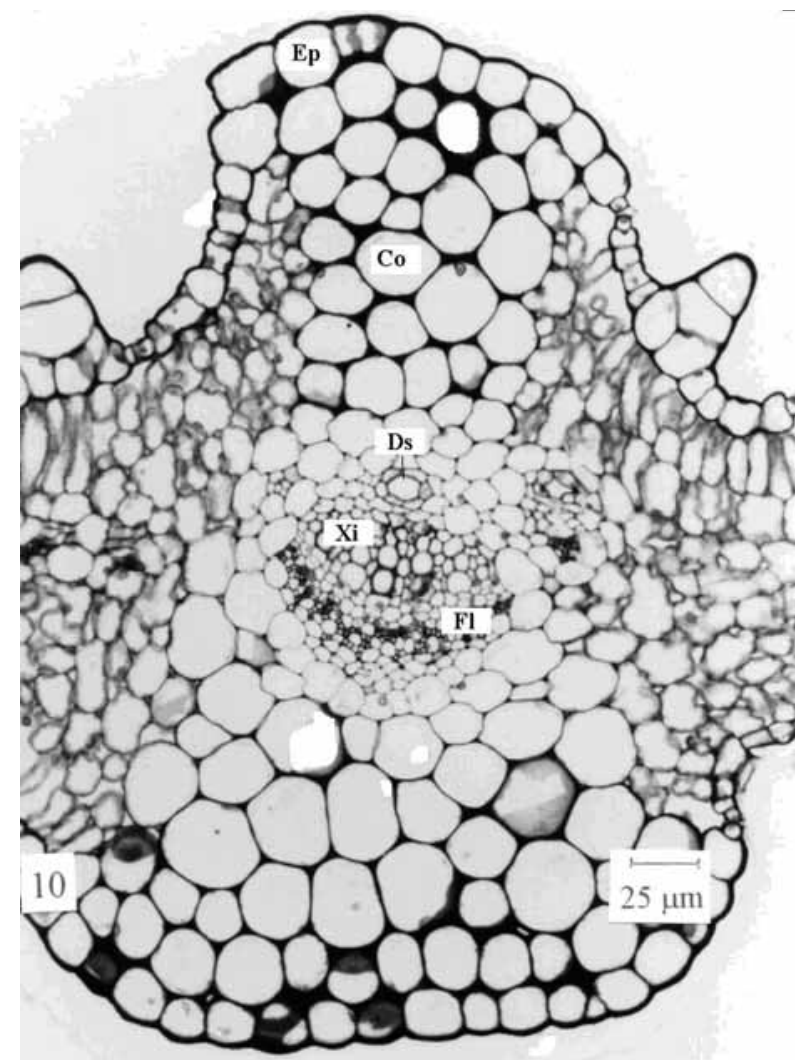

Figura 10. C. uniflora: Secção transversal da folha, mostrando o formato biconvexo da nervura central, epiderme uniestratificada (Ep), colênquima ( $\mathrm{Co})$, duto secretor (Ds), xilema (Xi) e floema (Fl).

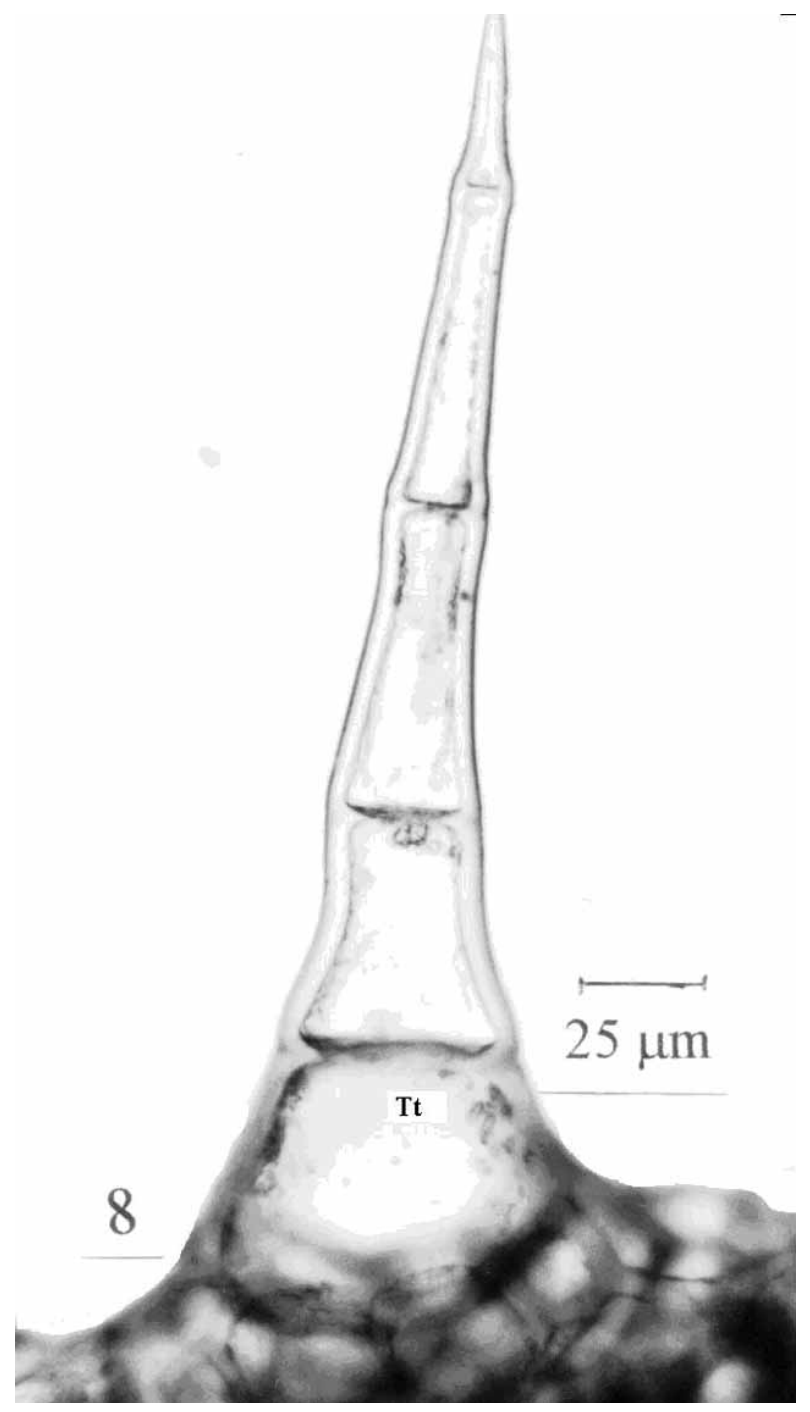

Figura 8. C. uniflora: Tricoma tector (Tt).

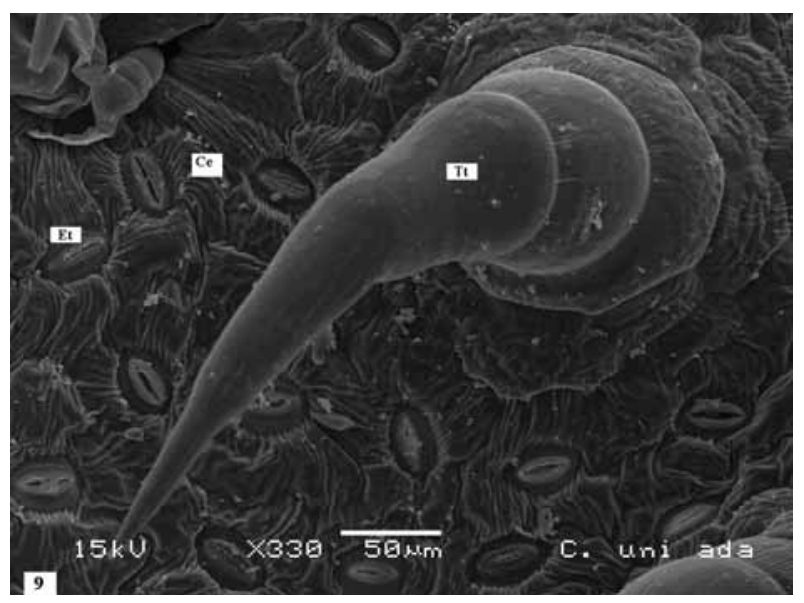

Figura 9. C. uniflora: Vista frontal da epiderme, face adaxial, evidenciando tricoma tector (Tt), estômatos (Et) e cutícula estriada (Ce) (MEV 330x). 


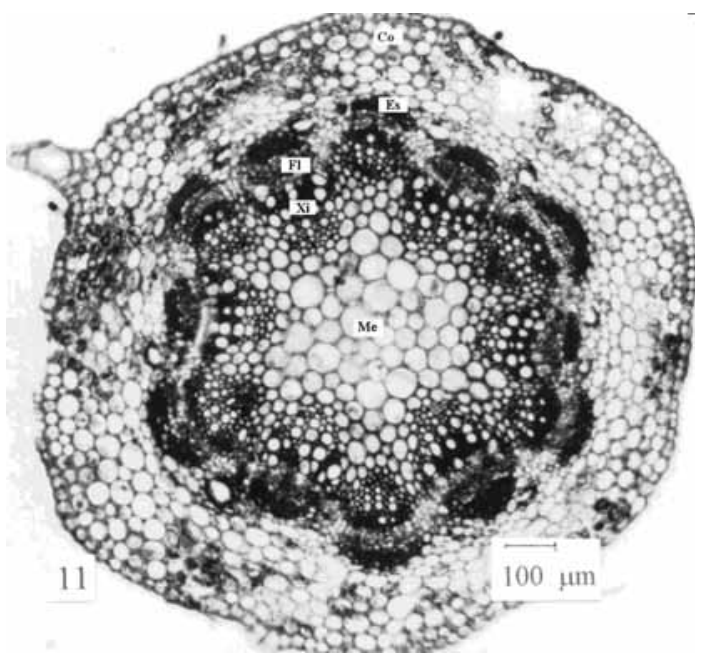

Figura 11. C. uniflora: Secção transversal do caule, indicando colênquima angular (Co), calota de fibras perivasculares $(\mathrm{Es})$, xilema $(\mathrm{Xi})$, floema $(\mathrm{Fl})$ e região medular (Me).

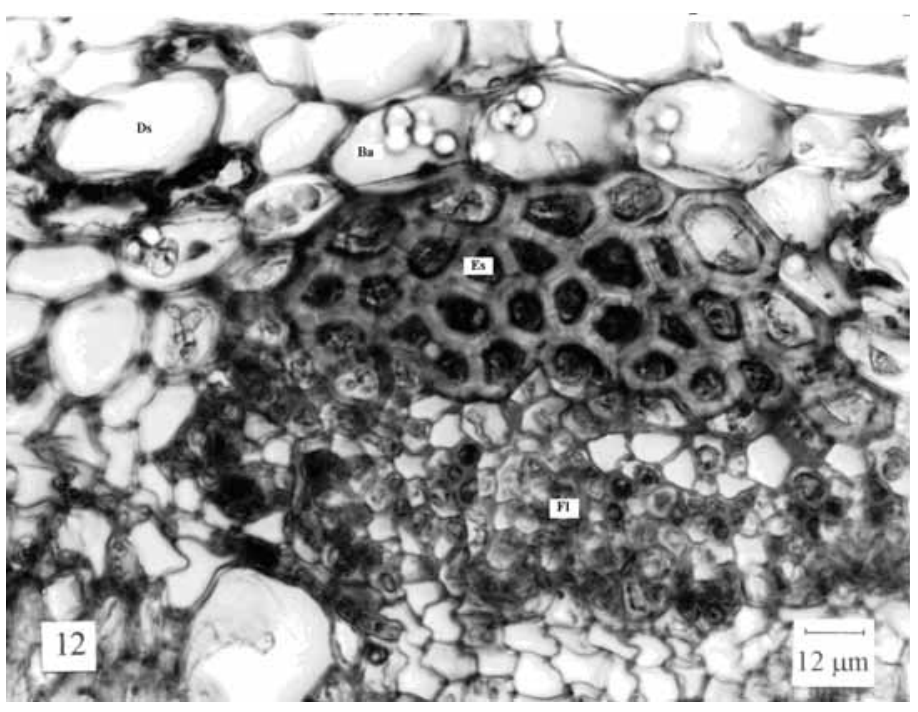

Figura 12. C. uniflora: Secção transversal do caule, evidenciando duto secretor (Ds), bainha amilífera (Ba), calota de fibras perivasculares (Es) e floema (Fl).

\section{REFERÊNCIAS}

Barroso GM 1991. Sistemática de angiospermas do Brasil. Viçosa: Universitária. v. 2.

Berlyn GP, Miksche JP 1976. Botanical microtechnique and cytochemistry. Ames: Iowa State University, p. 121, 276.

Cutter EG 1986. Anatomia vegetal: células e tecidos. 2.ed. São Paulo: Roca.

Esau K 1974. Anatomia das plantas com sementes. São Paulo: Blücher.

Flach A, Gregel B, Simionatto E, Silva UF, Zanatta N, Morel AF, Linares, CEB, Alves SH 2002. Chemical analysis and antifungal activity of the essential oil of Calea clematidea. Planta Med 68: 836-838.

Ferreira S, Roque NF, Gottlieb OR, Oliveira F 1978. Compostas medicinais do Brasil: estudo químico de Calea pinatifida. V Simpósio de Plantas Medicinais do Brasil, Ciência e Cultura: 32 (supl.): 83-85.

Ferreira ZS, Roque NF, Gottlieb OR, Oliveira F, Gottlieb HE 1980. Structural clarification of germacranolides from Calea species. Phytochemistry: 19: 14811484.

Foster AS 1949. Practical plant anatomy. 2. ed. Princeton: D. Van Nostrand, p. 218.

Guerrero MF, Puebla P, Carron R, Martin M, Arteaga L, Roman LS 2002. Assessment of the antihypertensive and vasodilator effects of ethanolic extracts of some Colombian medicinal plants. J Ethnopharmacol 80: 37-42.

Johansen DA 1940. Plant microtechnique. New York: McGraw Hill Book, p. 41, 193.

Jorge LIF, Pregnolatto BP, Chicourel EL, Zamariolli LA, Graciano RAS 1999. Anatomia e avaliação da atividade antimicrobiana in vitro de mil-folhas (Achillea millefolium L.). Rev Ciên Farm 20: 449458.
Karis PO, Ryding O 1994. Tribe Heliantheae. In: Asteraceae: Cladistics and Classification. Portland: Timber Press, p. 559-624.

Kohler I, Jenett-Siems K, Siems K, Hernandez MA, Ibarra RA, Berrendsohn WG, Bienzie U, Eich E 2002. In vitro antiplasmodial investigation of medicinal plants from El Salvador. Z. Naturforsch.57: 277-281.

Kraus JE, Arduin M 1997. Manual básico de métodos em morfologia vegetal. Rio de Janeiro: Edur, 198 p.

Lersten NR 1997. Occurrence of endodermis with a casparian strip in stem and leaf. Bot Rev 63: 265-271.

Machado Filho J 1930. Aruca, amebicida ideal. Arq. Biol. 34: 95-98.

Martinez VM, Sanchez FA, Joseph-Nathan P 1987. Thymol derivatives from Calea nelsonii. Phytochermistry 26: $2577-2579$.

Metcalfe CR 1979. The leaf: general topography and ontogeny of the tissues. In: Metcalfe CR \& Chalk L. Anatomy of the dicotyledons. Oxford: Clarendon Press. v. 1, p. 63-75.

Metcalfe CR, Chalk L 1950. Anatomy of dicotyledons: leaves, stem, and woods in relation to taxonomy with notes on economic uses. Oxford: Clarendon Press. v. 2.

Myiake ET, Akisue MK, Oliveira F 1986. Farmacognosia de aruca Calea pinnatifida Banks - Compositae. Rev Bras Farmacogn 1(Supl): 46-47.

Nascimento AM, Oliveira DCR, Albuquerque S 2002. Evaluation of trypanocidal activity from Calea uniflora (Heliantheae-Asteraceae) extracts. Rev Bras Farmacogn 12(Supl): 49-50.

Nascimento AM, Oliveira DCR 2004. A 5-deoxyflavone glycoside from Calea uniflora L. (Asteraceae). Biochem Syst Ecol 32: 1079-1081.

Nascimento AM, Salvador MJ, Candido RC, Albuquerque S, Oliveira DC 2004. Trypanocidal and antifungal activities of $p$-hidroxyacetophenone derivatives from Calea uniflora (Heliantheae, Asteraceae). 
Pharm Pharmacol 56: 663-669.

Neves LJ, Sá MFA 1991. Contribuição ao estudo das plantas medicinais Mikania glomerata Spreng. Rev Bras Farm 72: 42-47.

O’Brien TP, Feder N, Mccully ME 1965. Polychromatic staining of plant cell walls by toluidine blue O. Protoplasma 59: 368-373.

Ober AG, Fronczek FR, Fischer NH 1985a. Three benzofurans and a 1,4-dioxin derivative from Calea species: molecular structures of calebertin and caleteucrin. J Nat Prod 48: 242-248.

Ober AG, Urbatsch LE, Fischer NH 1985b. Germacranolides, calbertolides A, B and C from Calea berteriana. Phytochermistry 24: 1743-1745.

Ober AG, Urbatsch LE, Fischer NH 1986. Sesquiterpene lactones from Calea leptocephala. Phytochemistry 23: 467-469.

Ober AG, Urbatsch LE, Fischer NH 1987. Sesquiterpene lactones from Calea megacephala. Phytochemistry 26: 1204-1206.

Oliveira F, Akisue G, Akisue, MK 1991. Farmacognosia. São Paulo: Atheneu, p. 384-388.

Oliveira F, Lúcia M, Garcia LO 1993. Caracterização farmacognóstica da droga e do extrato fluido de mentrasto - Ageratum conyzoides L. Lecta 11: 63100.

Oliveira F, Rodrigues RFO, Kato ETM 1999. Estudo farmacognóstico da almécega-da-praia - Mikania conferta Gardn. Lecta 17: 43-68.

Oliveira F, Rodrigues RFO, Bastos DHM, Pereira FH 2000. Caracterização morfo-histológica e verificação da atividade microbiológica da espécie vegetal Mikania cordifolia Willd. Lecta 18: 33-63.

Ortega A, Lopez JDC, Maldonado EA 1989. trisnorsesquiterpene lactone and other sesquiterpenes from Calea crocinervosa. Phytochemistry 28: 2735-2736.

Ramos RR, Alarcon-Aguilar F, Lara-Lemus A, Flores-Saenz JL 1992. Hypoglicemic effect of plants used in Mexico as antidiabetics. Arch Med Res 23: 59-64.

Rodrigues RF, Oliveira F, Kato ETM 1996. Morfodiagnose da droga conhecida como cipó-almécega- Mikania malacolepsis Robinson. Rev Farm Bioquím USP 32: 37-44.

Roeser KR 1962. Die Nadel der Schwarzkiefer-Massenprodukt und Kunstwerk der Natur. Mikrokosmos 61: 33-36.

Rudall P 1994. Anatomy of flowering plants: an introduction to structure and development. 2. ed. Cambridge: Cambridge University.

Sass JE 1951. Botanical microtechnique. 2. ed. Ames: Iowa State College, p. 97.

Souza W 1998. Técnicas básicas de microscopia eletrônica aplicadas às Ciências Biológicas. Rio de Janeiro: Sociedade Brasileira de Microscopia Eletrônica, p. $1-44$.

Tavares ES, Gil VR, Viana VRC 2000. Anatomia do eixo vegetativo de Ageratum conyzoides L. (Asteraceae). Rev Bras Farm 31: 25-28.

Vaz L 1949. Aruca no tratamento da disenteria amebiana. Arq. Biol.33: 23-24

16(1):jan/mar. 2006 